\title{
Disposal practices and awareness of medicine waste management among general population of Delhi-National Capital Region, India
}

\author{
Rashmi Zalpuri ${ }^{1,2}$, Jai Kishore Sharma ${ }^{1}$, Rakhi Singh ${ }^{2 *}$, Laxmi Rawat ${ }^{2}$ \\ ${ }^{1}$ Amity Business School, Amity University, Noida, U.P., India. \\ ${ }^{2}$ Bio-Analytical Science Division, Shriram Institute for Industrial Research, Delhi, India.
}

\section{ARTICLE INFO \\ Received on: 28/05/2021 \\ Accepted on: 25/10/2021 \\ Available Online: 05/01/2022}

\section{Key words:}

Unused, expired, disposal system, disposal practices, medicine waste, crosssectional study.

\begin{abstract}
Not all the medicines manufactured every year are consumed and adversely vast amount of medicines go unused or expired. Unsafe handling and disposal practices of unused and expired medicines results in environmental hazards which is a source of concern. A cross-sectional survey was performed in Delhi-NCR, India among 500 respondents that reflected their awareness, behaviors and disposal practices for unused and expired drugs. Despite the fact that the majority of respondents were optimistic about disposing of unused and expired drugs, nearly more than half of the survey population were unsure of proper disposal procedures. A total of $268(53.6 \%)$ were aware of the problem of medicine waste; about $236(47.2 \%)$ read the directions for disposing of medications, and $121(24.2 \%)$ respondents were aware of drug take back system. The most common practice of disposal of unused and expired medicines among people surveyed were dumping in household garbage. With respect to the level of public awareness regarding the legal disposal management and destruction of the medicine wastes, the results revealed an urgent need of public information creating awareness using ecofriendly methods of disposing unwanted medicines among community.
\end{abstract}

\section{INTRODUCTION}

In today's culture, medicines are the most often available means of therapy on a regular basis to cure or avoid illnesses, as well as to improve physical and mental health. People take medications even for social comfort and psychological reasons. For the past century, medical innovation has resulted in a substantial improvement in life expectancy and quality of life. With the huge influx of information on health stories in magazines, newspaper, media, people are getting more involved in wellness and health items. As a result, it influence in stocking large number of medicines at home that may results in unused/ unwanted and expired medicines. The waste created from these drugs is extremely high. Today the disposal of medication waste is too risky and difficult, especially in highly populated developing country like India. The toxic discharge of improper and unsafe disposal of medications affects the environment and creates health

*Corresponding Author

Rakhi Singh, Shriram Institute for Industrial Research, Delhi, India. E-mail:rakhis1973@gmail.com concern like bio-medical wastes created during or after human or animal care in any hospitals (Pandey et al., 2020; Salgado et al., 2021). Unlike other forms of waste, it is particularly harmful to the organism's wellbeing.

Medicines are often tossed into dustbins and viewed as household waste due to a lack of legislation and understanding. The irresponsible disposal of unused and expired medicines may have inconvenience to children and animals by means of risky health issues. Not having the proper site for disposing the medicine waste, these waste may spread into groundwater and results in prominent source of pollutants in an aquatic environment (Komijani et al., 2021). Many efforts are being done around the world to determine proper disposal techniques.

Studies unveiled that due to improper discard of medicines wastes in toilet or sink may enter and can pollute the nature hood (Comeau et al., 2008; Ruhoy and Daughton, 2007). Also can be discharged into the environment when are disposedoff in the household garbage or dustbins that eventually ends up as leachates in landfills (Barnes et al., 2004).

A random survey in Sweden (Persson et al., 2009) revealed that the storage of unused medicines are preferred rather 
disposing by flushing down into toilet or sinks and are returned directly to the pharmacy. Even in a Dutch study carried in 1990s, more than $80 \%$ of the participants returned unused medicines either to pharmacy of chemical waste facility as their concern towards environment pollution (Blom et al., 1996). Studies conducted in the United States (Kotchen et al., 2009) stated that about $45 \%$ of participants were aware of environmental pollution and returned unwanted medications to pharmacies. However, prevalence of improper disposal practice suggested issues of environmental awareness accounts for disposal patterns partially with respect to disposal of medicines. Also, from the study carried in Kuwait, it is evident that education status may not be associated with the awareness about the environment (Abahussain and Ball, 2007).

In Middle Eastern nations, Asian and most African countries, number of health and environmental issues is increasing day by day as a result of improper and unsafe disposal of medicines (Nepal et al., 2020). In another surveys, it was found that in developing countries like India, China, Bangladesh, and Ghana, the commonly found practice for disposal of unwanted medicines was discarding in the household garbage, eventually ending up in dumping area (Ferronato and Torretta, 2019; Insani et al., 2020).

General population must be aware of the pertinent practice of disposing of unused and unwanted medicines. Yet, improper drug disposal practice is common among different parts of the world. No exhaustive study has been conducted around the management of disposal for unwanted medication in India. Such kind of data is inevitable to develop proper measures with increase in community awareness with respect to drug disposal along with its related harmfulness. This study will evaluate the disposal practice and awareness of management systems of unwanted medicines in common population of Delhi NCR (National Capital Region), India.

\section{MATERIALS AND METHODS}

\section{Study design and study population}

This was a questionnaire-based cross-sectional survey. The study was conducted in the local population of DelhiNCR, India from November 2020 to January 2021. The sample included people over the age of 18 (248 males and 252 females) who were in good mental health. There was no upper age limit. As seen in Table 1, respondents provided potential responses to the question of whether they were mindful of the proper disposition of unused and outdated medications. According to the results of this report, approximately $53.6 \%$ of respondents have good knowledge

\section{Study instrument}

Two parts were there in the questionnaire, of which first part consisted of participants' information regarding age, gender, level of education and marital status, ways of acquiring different types of medicines. Second section carried questionnaire on the disposal practices and attitudes concerning disposal of unused and expired medications. The respondents were required to choose from the given descriptive questionnaires on their disposal practices. The questionnaires were made in English language. The questionnaires were translated to native language and back to English wherever required to avoid any confusion. Cronbach's alpha test was performed to check the reliability assessment.

\section{Method for collection of data and analysis}

A structured questionnaire was prepared to investigate the knowledge with respect to the disposition of expired and left over drugs. The purpose of the study was explained to every participants and ensuring their confidentiality. All questionnaires filled were checked thoroughly for collected data and later fed into a spreadsheet dataset. For analysis of the data, Statistical Package for Social Science version 22 was used.

\section{RESULTS AND DISCUSSION}

\section{Socioeconomic information}

After interviewing many people, 500 participants decided to take part in the study. Response rate of the participant was found to be $100 \%$. Out of 500 participants, $136(27.2 \%)$ women and $364(72.8 \%)$ were found to be men. Most of the (269; $53.7 \%$ ) participants were more than 46 years. Participants having secondary education were $60(21.4 \%)$, graduates $258(68.4 \%)$ and illiterate $10(1.8 \%)$ (Table 1$)$. Cronbach's alpha was found to be 0.70 .

\section{Analysis of respondents practice on unused medication disposal}

Throwing unused drugs in garbage bins was the most common method of disposal (61.2\%), accompanied by offering them to friends or relatives $(9 \%)$. Some respondents $(5.6 \%)$ retain leftover medications until they expire at home. Respondents $(3.8 \%)$ burn the medicines along with household garbage, and $6.6 \%$ of respondents donate medicines to hospitals. Returning of unused drugs to pharmacies was thought to be the safest choice by around $7.6 \%$ respondents. Table 3 lists the disposal of unused medicines value given by respondents.

In this study, population type gender, age, marital status, education, and occupation were analyzed. The outcome of this study was evaluated by means of manual statistics using analysis of variance $p$-value and $f$-value where $p$-value was found to be less than 0.01 and $f$-value to be between 2.0 and 9.0. Graphical presentation of questionnaire-based cross-sectional survey w.r.t. study design is as given in Figure 1.

\section{Analysis of respondents practice on expired medication disposal}

Throwing expired drugs in garbage bins (71.4\%) was the most common method of disposal, followed by flushing them down toilets $(14.8 \%)$. Few respondents $(2.8 \%)$ said they were unsure what to do with expired medications, whereas $3.2 \%$ and $4.6 \%$ said they would return drugs to the pharmacy and send medicines to friends or family meanwhile. Table 4 shows the disposal of expired medicine value given by respondents.

\section{Awareness of disposal system}

The usual practice of discarding the unwanted leftover and expired medicines is by throwing it into the household garbage or dustbins or flushed into toilet or sink. These impractical ways ends up in polluting the environment. In this survey, major 
Table 1. Respondents' knowledge of how to dispose of unused and expired medications.

\begin{tabular}{llcc}
\hline Variables & Demographic parameters & Number of responses & (\%) of responses \\
\hline Gender & Male & 364 & 72.80 \\
& Female & 136 & 27.20 \\
Age & $19-30$ & 104.5 & 20.90 \\
& $31-45$ & 127 & 25.40 \\
Marital status & 46 -above & 268.5 & 53.70 \\
& Single & 207.5 & 41.50 \\
Level of education & Married & 292 & 58.40 \\
& Illiterate & 10 & 1.80 \\
Occupation & Primary & 33 & 8.40 \\
& Secondary & 60 & 21.40 \\
& University & 258 & 68.40 \\
& University students & 77 & 15.40 \\
& Unemployed & 13 & 2.60 \\
& Employed & 253.5 & 156.5 \\
& Others & 50.70 & 31.30 \\
\end{tabular}

population evaluated was above age group of 46 years $(53.7 \%)$ and predominantly male gender $(72.8 \%)$. Level of education of more than half of the participants $(68.4 \%)$ was university graduates. Considerable sizes of the participants were literate (98.2\%). About $15.2 \%$ of the respondents were university graduates; $50.7 \%$ of them were employed and $31.3 \%$ were having different occupation. Being literate helps the population to perceive and decipher the significance of proper disposing of unused and expired medicines. Moreover, being literate can help in understanding the adverse effect to the environment. This survey reflects that half of the

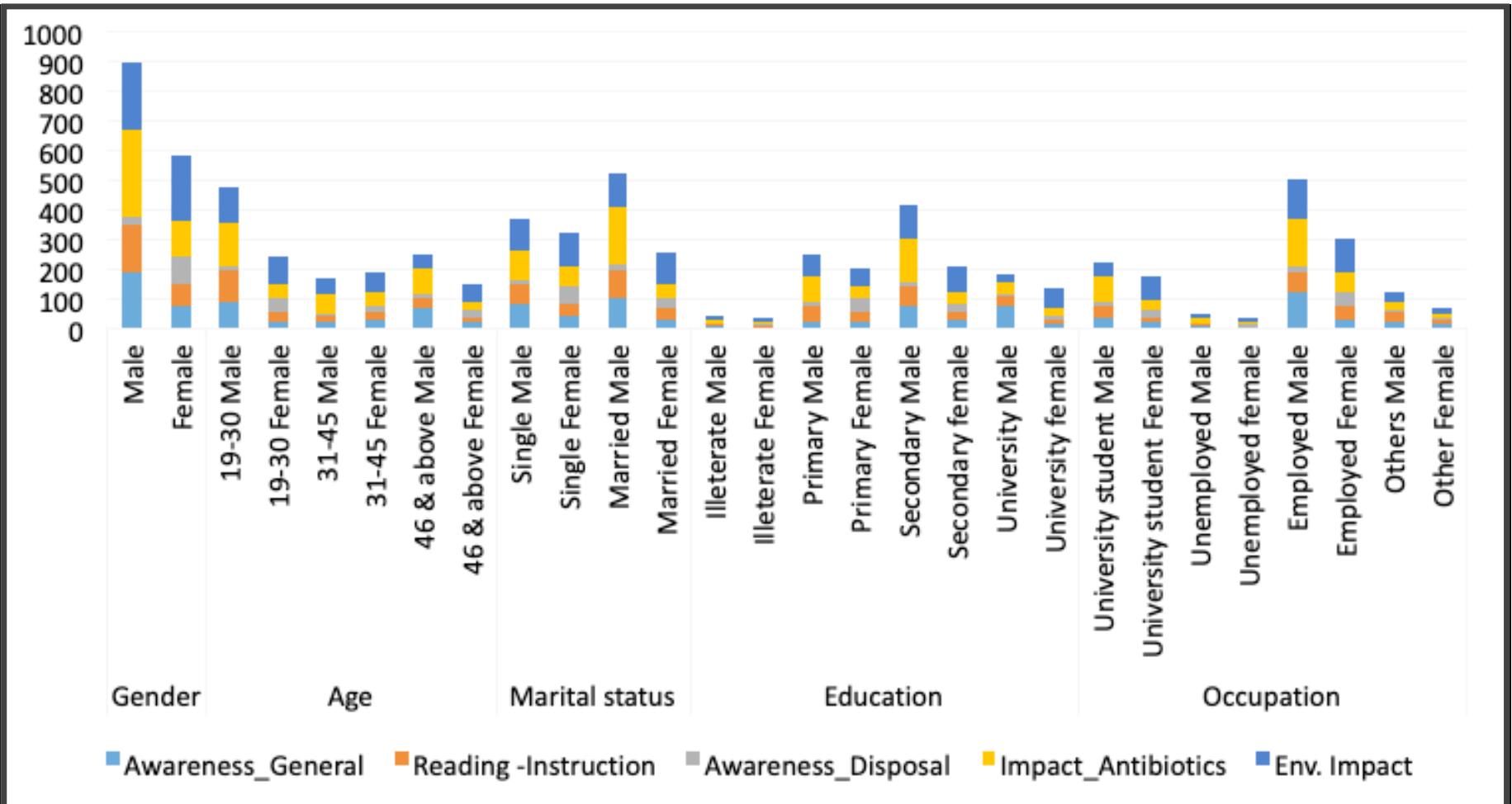

Figure 1. Graphical presentation of questionnaire-based cross-sectional survey w.r.t. study design. 
Table 2. Respondents' knowledge of how to dispose of unused and expired medications.

\begin{tabular}{|c|c|c|c|}
\hline \multirow{2}{*}{ No } & \multirow{2}{*}{ Questions } & \multicolumn{2}{|c|}{ Responses nos. (\%) } \\
\hline & & Yes & No \\
\hline 1 & Are you aware of the problem of medication waste? & $268(53.6 \%)$ & $232(46.4 \%)$ \\
\hline 2 & Have you ever read the directions for disposing of medications? & $236(47.2 \%)$ & $264(52.8 \%)$ \\
\hline 3 & Are you know about the "drug-take-back system?" & $121(24.2 \%)$ & $379(75.8 \%)$ \\
\hline 4 & Do you know that changing antibiotics often or not completely will lead to drug resistance? & $415(83 \%)$ & $85(17 \%)$ \\
\hline 5 & $\begin{array}{l}\text { Are you conscious that unsafe storage of unused and expired drugs may have a negative impact on the atmosphere } \\
\text { and your health? }\end{array}$ & $446(89.2 \%)$ & $54(10.8 \%)$ \\
\hline
\end{tabular}

respondents $(53.6 \%)$ were aware of the problem with medical waste. Out of 500, only 236 participants have read the directions of medicines disposal. Hardly $24.2 \%$ respondents were aware of the "drug take back program." However, majority of them with more than $80 \%$ were having the knowledge of antibiotics resistance and are conscious of the negative impact of unsafe storage on the health and environment (Table 2).

\section{Penalty for violation of disposal system}

"As per Government of India, Ministry of Health and Family Welfare (Department of Health), The Drugs and Cosmetics Act and rules disposal of sewage and effluents (solid, liquid, and gas) from the manufactory shall be in conformity with the requirements of Environment Pollution Control Board. As per Environment Protection Act 1986, chapter III (PREVENTION, CONTROL AND ABATEMENT OF ENVIRONMENTAL POLLUTION) whoever fails to comply with or contravenes any of the provisions of this Act, or the rules made or orders or directions issued thereunder, shall, in respect of each such failure or contravention" (Environment Protection Act, 1986):

1. Punishable with detention to 5 years or fine of $1,00,000$ rupees, in case the failure continues, additional fine of 5,000 rupees will be imposed.

2. The lawbreaker shall be indictable with imprisonment which may extend to 7 years, in case if the infringement continues past 1 year after the date of judgment.

Table 3. Disposal of unused medicines.

\begin{tabular}{lcc}
\hline Disposal practice of unused medicines & Nos. & \% \\
\hline Throwing medicines away in household garbage & 306 & 61.2 \\
Donating medicines to hospital & 33 & 6.6 \\
Giving medicines to friends or relatives & 45 & 9 \\
Returning medicines back to pharmacy & 38 & 7.6 \\
Keeping medicine at home until expired & 28 & 5.6 \\
Flushing medicines in toilet & 31 & 6.2 \\
Burning medicines & 19 & 3.8 \\
Total & 500 & 100 \\
\hline
\end{tabular}

\section{Practice of disposal system in academic institutes as per the regulations}

Waste management related to the collection of wastes and educational-projects represent key steps in fostering the sustainability concept. Regulations pertaining to academic institute waste, "Bio-medical Waste (Management and Handling) Rules, 1998 were notified by the Ministry of Environment and Forests under the Environment (Protection) Act, 1986" (BioMedical Waste Management). Some of the provisions, which are applicable to academic institutions, viz., teaching hospitals and non-profit research institutes including nursing homes/clinics, hospitals, animal specialty institutions, pathological and diagnostic laboratories, research institutions/labs, forensic laboratories are:

a) Determination of requirement for hazardous waste to be made by professionals

b) In institutes removal of harmful waste as per the respective disposal management.

c) Segregation of waste as per the waste category (Coded bags).

d) Academic entities should decide the duration for hazardous waste determinations

e) Framing of Laboratory Management Plan, for waste management practices.

\section{Prospective waste management systems for expired and unused medicines}

Various strategical methods like landfills; return to donor or manufacturer; waste immobilization; burning in open containers; incineration at high temperatures and chemical decomposition are set around the world to manage solid wastes. Dumping must be sited at appropriate place with highly engineered sanitary landfills to minimize entry possibility of leachates into the environment. Burning of pharmaceuticals in open containers can release toxic pollutants contaminating the atmosphere. Pharmaceutical waste immobilization can be carried out by mixing with lime, cement and water using unsophisticated equipment (WHO, 1999). Incineration at high temperature cannot be afforded by many countries as it is expensive and require sophisticated chemical waste disposal facilities. Moreover, chemical inactivation can be time consuming and tedious.

Shelf life extension program, established by department of Defense, USA and United States Food and Drug Administration (USFDA) in 1986 with the goal to conserve resources by 
Table 4. Disposal of expired medicines.

\begin{tabular}{lcc}
\hline Disposal practice for expired medicines & Nos. & \% \\
\hline Placing medicine in the household garbage & 357 & 71.4 \\
Flushing medicine in toilet & 74 & 14.8 \\
Giving medicines to friends or relatives & 23 & 4.6 \\
Returning medicines back to pharmacy & 16 & 3.2 \\
Do not know & 14 & 2.8 \\
Other & 16 & 3.2 \\
Total & 500 & 100 \\
\hline
\end{tabular}

increasing the shelf life of medication stocks in army (Diven et al., 2015; Khan et al., 2014). Such programs may not tackle the global problem related to pharmaceutical wastes but can reduce the volume of burden. Take-back program of prescription drug also reduces environmental pollution by facilitating a safe disposal of unwanted medicines from the community. Drug take back programs are being followed in developed countries like United States, Sweden, Germany, United Kingdom, and Australia successfully and achieving the goals (Kadam et al., 2016). Recycling programs of medicine wastes containing expensive Active Pharmaceutical Ingredient (API) can be highly effective economically. Such an approach could be promising, whereby the API can be extracted form medicine wastes and formulated again to regain its value (Alnahas et al., 2020).

To overcome the adverse outcome of environment contamination, there is a need for educating the consumers and issuing the minimal prescribed medicines during clinic visit. Yet, in developing countries like India, the availability of over the counter medicines contribute in the major proportion of medicine wastes. As a one-off issue, there is a need of preliminary surveys at various levels with proper feedback to understand and customizing programs as per local need. An ideal practice may not be feasible as the option of disposal methods may vary according to the situations. Government should implement proper channeled system in association with drug regulatory bodies, pollution control board, NGOs and other civil societies regarding utilization, storage and disposal of left over drugs and drug take back programs.

In context to the future prospective and extension of work on large scale for educating people on proper disposal procedures of unused and expired medicines, the proper awareness programs and trainings among the mass population should be organized by respective agencies along with the increase in number of service provider for waste management. Various reasons contributing to the root cause of unawareness among population are lack of knowledge about the health hazards due to health-care waste, absence of systemic waste management and disposal systems, inadequate training, insufficient financial and human resources and minimum concern to proper disposition of health-care waste.

\section{CONCLUSION}

The study revealed that the practice of medicine disposal majorly depends on socio-economic culture and prevalence of regulatory guidelines of the country. In the study, large percentages of the respondents were unaware of drug-take back programs. On the other hand, the majority of respondents were positive about the dangers of unused or expired drugs. A pressing process is the need to raise general consciousness on how to dispose properly the unwanted and expired drugs. Community pharmacists can play an important role in promoting proper waste management in the major cities of India. Implementation of different disposal programs and awareness regarding the disposal of unused and expired pharmaceuticals should be improved in developing country like India which is also a major center for manufacture of pharmaceuticals.

\section{AUTHOR CONTRIBUTIONS}

Data gathering and idea owner of this study is Rashmi Zalpuri. All other authors contributed to data construal, framing the article, and reviewing it. They also agreed to submit in the current journal and finally giving the consent for publication.

\section{CONFLICTS OF INTEREST}

The authors report that there is no conflict of interest.

\section{FUNDING}

This study received no specific funding from any agency/ sector.

\section{REFERENCES}

Abahussain EA, Ball DE. Disposal of unwanted medicines from households in Kuwait. Pharm World Sci, 2007; 29:368-73.

Alnahas F, Yeboah P, Fliedel L, Abdin AY, Alhareth K. Expired medication: societal, regulatory and ethical aspects of a wasted opportunity. Int J Environ Res Public Health, 2020; 17:787.

Barnes KK, Christensen SC, Kolpin DW, Focazio MJ, Furlong ET, Zaugg SD, Meyer MT, Barber LB. Pharmaceuticals and other organic waste water contaminants within a leachate plume down gradient of a municipal landfill. Ground Water Monit Rem, 2004; 24:119-26.

Bio-Medical Waste Management. Available via https://cpcb.nic. in/bio-medical-waste-rules/

Blom ATG, De Bruijn JCMJ, Van De Vaart FJ. How consumers deal with the remainders of unused prescription drugs. Pharm Weekbl, $1996 ; 131: 102-7$.

Comeau F, Surette C, Brun GL, Losier R. The occurrence of acidic drugs and caffeine in sewage effluents and receiving waters from three coastal watersheds in Atlantic Canada. Sci Total Environ, 2008; 396:132-46.

Diven DG, Bartenstein DW, Carroll DR. Extending shelf life just makes sense. Mayo Clin Proc, 2015; 90:1471-4.

Environment Protection Act. 1986. Available via https://www. indiacode.nic.in/bitstream/ep act 1986

Ferronato N, Torretta V. waste mismanagement in developing countries, a review of global issues. Int J Environ Res Public Health, 2019; 16(6):1060

Insani WN, Qonita NA, Jannah SS, Nuraliyah NM, Supadmi W, Gatera VA, Alfian SD, Abdulah R. Improper disposal practice of unused and expired pharmaceutical products in Indonesian households. Heliyon, 2020; 6(7):e04551.

Kadam A, Patil S, Patil S, Tumkur A. Pharmaceutical waste management an overview. Indian J Pharm Pract, 2016; 9(1):1-8.

Khan SR, Kona R, Faustino PJ, Gupta A, Taylor JS, Porter DA, Khan M. United States Food and Drug Administration and Department of Defense Shelf-Life Extension Program of Pharmaceutical Products: progress and promise. J Pharma Sci, 2014; 103:1331-6.

Kotchen M, Kallaos J, Wheeler K, Wong C, Zahller M. Pharmaceuticals in wastewater: behavior, preferences, and willingness to pay for a disposal program. J Environ Manage, 2009; 90:1476-82. 
Komijani M, Shamabadi NS, Shahin K, Eghbalpour F, Tahsili MR, Bahram M. Heavy metal pollution promotes antibiotic resistance potential in the aquatic environment. Environ Pollut, 2021; 274:116569.

Nepal S, Giri A, Bhandari R, Chand S, Nepal S, Aryal S, Khanal P, Moktan JB, Shastry CS. Poor and unsatisfactory disposal of expired and unused pharmaceuticals: a global issue. Curr Drug Saf, 2020; 15(3):167-7.

Pandey S, Divekar R, Singh A, Sainath S. Bio-medical waste management processes and practices adopted by select hospitals in Pune. Oper Supply Chain Manage Int J, 2020; 13(1):31-47.

Persson M, Sabelstrom E, Gunnarsson B. Handling of unused prescription drugs-knowledge, behaviour and attitude among Swedish people. Environ Int, 2009; 35:771-4.

Ruhoy IS, Daughton CG. Types and quantities of leftover drugs entering the environment via disposal to sewage - revealed by coroner records. Sci Total Environ, 2007; 388:137-48.

Salgado MAR, Salvador MR, Baldoni AO, Thomé RG, Santos HB. Evaluation of the potential environmental risk from the destination of medicines: an epidemiological and toxicological study. DARU J Pharm Sci, 2021.
WHO. Guidelines for safe disposal of unwanted pharmaceuticals in and after emergencies: interagency guidelines. World Health Organization, Geneva, Switzerland, 1999. Available via WHO/EDM/PAR/99.2

\section{How to cite this article:}

Zalpuri R, Sharma JK, Singh R, Rawat L. Disposal practices and awareness of medicine waste management among general population of Delhi-National Capital Region, India. J Appl Pharm Sci, 2022; 12(01):078-083. 